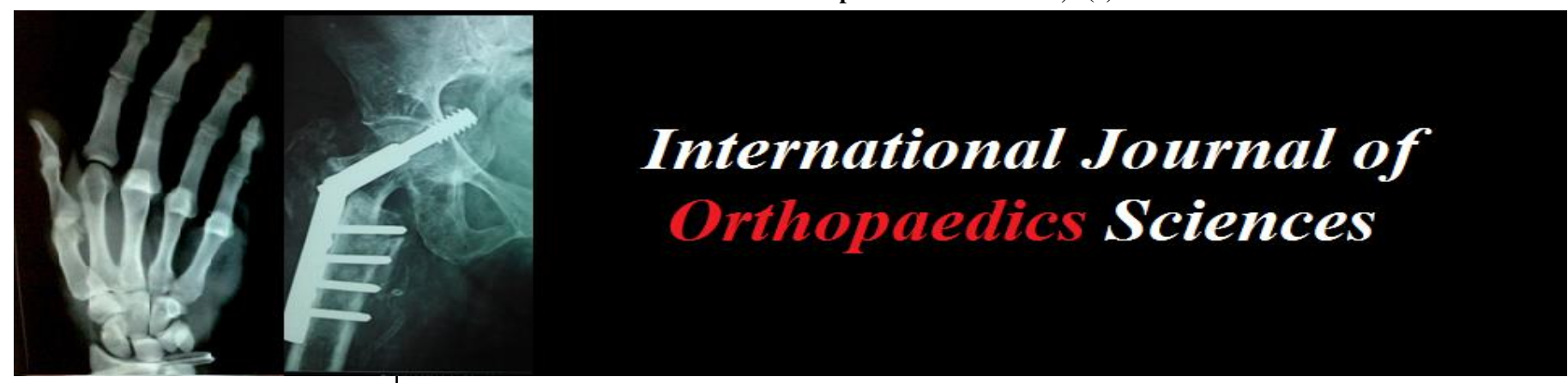

E-ISSN: 2395-1958

P-ISSN: 2706-6630

IJOS 2020; 6(1): 692-694

(C) 2020 IJOS

www.orthopaper.com

Received: 24-11-2019

Accepted: 28-12-2019

Vijay Mahantesh Sunkad Department of Orthopedics KIMS, Koppal, Karnataka, India

Vijay Mahanth Prasad Department of Orthopedics KIMS, Koppal, Karnataka, India

Corresponding Author: Vijay Mahantesh Sunkad Department of Orthopedics KIMS, Koppal, Karnataka, India

\section{The study of outcome of non comminuted lower end radius fractures treated by closed reduction and internal fixation with percutaneous pinning}

\author{
Vijay Mahantesh Sunkad and Vijay Mahanth Prasad
}

DOI: https://doi.org/10.22271/ortho.2020.v6.i11.1946

\begin{abstract}
Introduction: Fractures of the distal radius constitute one of the most common skeletal injuries treated by orthopaedic surgeons. Colle's fracture was first described by Abraham Colle of Dublin in Ireland. There are variety of treatment modalities in treating extraarticular non-comminuted fractures of distal radius. Each one has got their own advantages and disadvantages. Increased life expectancy of the population increases and as accidents also increase, the incidence of this fracture is expected to increase. Percutaneous pinning is one of the most simple, cost effective, easy procedure with good results. This study was conducted to analyze the outcome of Distal Radial Fractures treated with closed reduction and percutaneous pinning.

Materials and Methods: This is a prospective study of 30 cases of distal radius fractures. noncomminuted aged between 20 to 70 years of age. They were treated with closed reduction and internal fixation with Percutaneous pinning with 2-3 K-wires. Postoperatively they were immobilized with below elbow dorsal slab. After 3 weeks slab was removed and physiotherapy started, K-wires were removed after 6 weeks. Post operative xrays were done at 3 weeks, 6 weeks and 6 months.

Results: There were 30 cases in our study. 60\% (18) males and 40\% (12) females. The mean age of the patients was 52 years. The mechanism of injury in most cases was fall on out stretched hand $76.6 \%$ (23). The side of involvement was right in 56\% (17) and 44\% (13) in left hand. 66\% (19) belonged to type A, $34 \%$ (10) belonged to Type C according to Fernandez classification. 54\% (16) patients belonged to A type, $36 \%$ (11) belonged to type B as per AO classification. 60\% (18) showed excellent outcome under subject evaluation, $67 \%$ (20) patients showed excellent end results. Total 13\% (4) showed complications in the study. Among them 7\% (2) were pin tract infection, followed by malunion and Reflex Sympathetic Dystrophy each 3\% (1).
\end{abstract}

Keywords: extraarticular distal radius fracture, K-wire, closed reduction, percutaneous pinning

\section{Introduction}

Fractures of the distal radius constitute one of the most common skeletal injuries treated by orthopaedic surgeons. Colle's fracture was first described by Abraham Colle of Dublin in Ireland. He recognized high incidence of residual deformity when injury had healed and noted the cases in which the reduction could be carried out and marked propensity for the deformity to recur ${ }^{[1]}$. This fracture usually results from low energy trauma in the elderly with low functional demand ${ }^{[2]}$. Increased life expectancy of the population increases and as accidents also increase, the incidence of this fracture is expected to increase. The residual deformity of the wrist as a result of malunion is unsightly. It adversely affects wrist motion and hand function by interfering with the mechanical advantage of the extrinsic hand musculature ${ }^{[3,4]}$. In many cases there is weakness of handgrip and return to preinjury activity level becomes impossible. There are lot of treatment modalities which included closed reduction and casting, closed reduction and Percutaneous pinning by different methods such as Kapandiji intrafocal pinning, transradial styloid pinning ${ }^{[5]}$. Also closed reduction and external fixation by means of ligamentotaxis to realign fracture displacement; open reduction and internal fixation by different approach such as dorsal approach, volar approach ${ }^{[2,6]}$. Each one has got their own advantages and disadvantages. The method of Percutaneous pinning is ideally recommended as a simple way of providing additional stability to immobilization in a cast in extra-articluar 
fractures of distal radius in which anatomical reduction is obtained by closed reduction ${ }^{[7,8]}$. Percutaneous pinning is one of the most simple, cost effective, easy procedure with good results. This study was conducted to analyze the outcome of Distal Radial Fractures treated with closed reduction and percutaneous pinning.

\section{Objectives}

1. To analyze the outcome of Distal radius fractures treated with closed reduction and percutaneous pinning.

\section{Materials and Methods}

Source of data: 30 cases of distal radius fractures non comminuted aged 20 to 70 years admitted in KIMS, Koppal

Inclusion criteria: All extraarticular fractures of distal radius with displacements.

Exclusion criteria: Intraarticular distal radius fracturespresenting later than 2 weeks of injury, polytrauma patients, patients with open fractures.

\section{Methods}

This prospective study consists of 18 male and 12 female cases of age group between 20 to 70 years. The fractures were classified according to the AO classification, using the pre operative anteroposterior and lateral roentgenogram (Figure 1). All the 30 patients had AO type A2 fractures. Radial length, palmar tilt and radial angulation were measured.
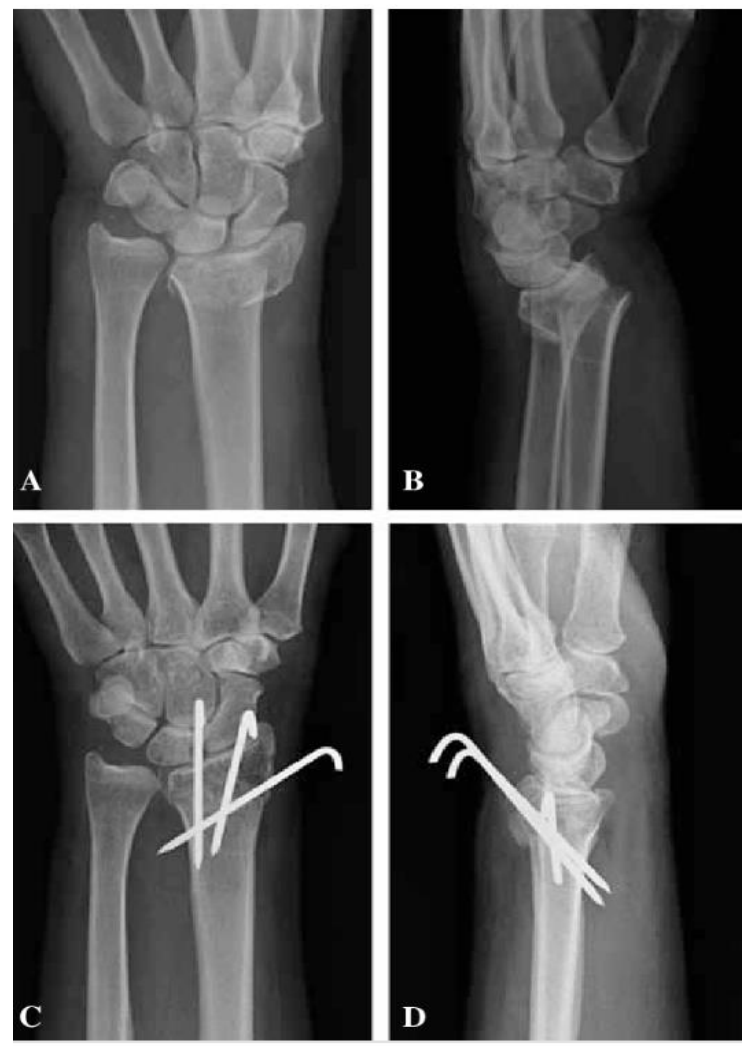

Fig 1: The pre operative anteroposterior and lateral roentgenogram

\section{Operative Procedure}

The patients were treated with closed reduction and internal fixation with Percutaneous pinning with two k-wires. Closed reduction of the fracture was achieved by longitudional traction and direct pressure over the displaced fragment under anesthesia. Reduction was checked under image intensifier in both anteroposterior and lateral planes. With the fracture in reduced position the first $\mathrm{K}$ wire of 1.5-2.0 $\mathrm{mm}$ was inserted from the dorsolateral aspect of the distal radius fragment across the fracture into the proximal fragment under image intensifier guidance. A second k-wire was passed from dorso medial aspect from distal to proximal fragment. A sterile dressing was applied to prevent skin irritation. Postoperatively they were immobilized with below elbow dorsal slab. After 3 weeks slab was removed and physiotherapy started, K-wires were removed after 6 weeks. Results were evaluated clinically and radiologically at 3 weeks, 6 weeks and 6 months.

\section{Results}

There were 30 cases in our study. $60 \%$ (18) males and $40 \%$ (12) females. The mean age of the patients was 52 years. The mechanism of injury in most cases was fall on out stretched hand $76.6 \%$ (23). The side of involvement was right in $56 \%$ (17) and $44 \%$ (13) in left hand.

Table 1: Cases as per fernandez classification

\begin{tabular}{|c|c|c|}
\hline Fernandez type & Cases & Percentage \\
\hline Type I & 19 & $66 \%$ \\
\hline Type II & 1 & $10 \%$ \\
\hline Type III & 10 & $34 \%$ \\
\hline Total & 30 & $100 \%$ \\
\hline
\end{tabular}

$66 \%$ (19) belonged to type A, 34\% (10) belonged to Type C

Table 2: Cases as per AO Classification

\begin{tabular}{|c|c|c|}
\hline AO Type & Cases & Percentage (\%) \\
\hline A & 16 & $54 \%$ \\
\hline B & 11 & $36 \%$ \\
\hline C & 3 & $10 \%$ \\
\hline Total & 30 & $100 \%$ \\
\hline
\end{tabular}

$54 \%$ (16) patients belonged to A type, 36\% (11) belonged to type B

Table 3: Result of functional outcome analysis

\begin{tabular}{|c|c|c|c|c|}
\hline Result & \multicolumn{2}{|c|}{ Subject evaluation } & \multicolumn{2}{c|}{ End result } \\
\hline & Cases & Percentage (\%) & Cases & Percentage (\%) \\
\hline Excellent & 18 & $60 \%$ & 20 & $67 \%$ \\
\hline Good & 8 & $27 \%$ & 7 & $23 \%$ \\
\hline Fair & 3 & $10 \%$ & 2 & $7 \%$ \\
\hline Poor & 1 & $3 \%$ & 1 & $3 \%$ \\
\hline
\end{tabular}

$60 \%$ (18) showed excellent outcome under subject evaluation, $67 \%$ (20) patients showed excellent end results.

Table 4: Complications

\begin{tabular}{|c|c|c|}
\hline Complications & Cases & Percentage (\%) \\
\hline Pin tract infection & 2 & $7 \%$ \\
\hline Malunion & 1 & $3 \%$ \\
\hline Reflex Sympathetic Dystrophy & 1 & $3 \%$ \\
\hline Total & 4 & $13 \%$ \\
\hline
\end{tabular}

Total 13\% (4) showed complications in the study. Among them 7\% (2) were pin tract infection, followed by malunion and Reflex Sympathetic Dystrophy each 3\% (1).

\section{Discussion}

Fractures of the lower end of radius are increasing in incidence with increase in life expectancy ${ }^{[9]}$. several studies by Jupiter ${ }^{[9]}$, Cooney ${ }^{[6]}$, Ericson ${ }^{[10]}$ Porter ${ }^{[11]}$ have suggested that there is a direct relationship between anatomical result and functional outcome ${ }^{[2,11,12]}$. but most older patients do relatively well in spite of obvious deformity ${ }^{[2,6,13-15]}$.

Although several studies on the use of Percutaneous $\mathrm{k}$ wire for the stabilization of distal radius fractures have been published, ${ }^{[5,16-18]}$ their use in elderly remain uncertain as seen by McQueen ${ }^{[12]}$.

Percutaneous pinning with $\mathrm{K}$-wire was first recommended by Green as a simple and inexpensive procedure ${ }^{[19]}$. 
In our study majority were men $60 \%$ and $40 \%$ women. This might be because of the fact men were the outdoor workers and were ready for surgery.

$76.6 \%$ of them were due to fall, followed by RTA and a case reported to be due to fight. $17 \%$ (5) patients were associated with injuries. Patients associated with injuries in same limb were excluded from the study.

$60 \%$ of them showed excellent outcome according to subject evaluation and $67 \%$ had excellent end result outcome, which was lower than the study by Abhishek K Das et al. ${ }^{[20]}$ the reason was patients with extra- articular fractures with dorsal comminution and fractures with simple intra-articular fractures were also treated with Percutaneous pinning.

The complications encountered in our study were $13 \%$ among them $7 \%$ were pin tract infection followed by Malunion $1 \%$ and RFD $1 \%$. The pin tract infection were treated and cured by antibiotics. The complication of malunion was due to the patient lost the followed up and removed the slab by himself prematurely and presented late to us for follow up.

\section{Conclusion}

The present study showed that the closed reduction with Percutaneous pinning under $\mathrm{C}$-arm is a simple, minimally invasive technique, which provides extra stability in the treatment of extraarticular fractures distal end of radius with good anatomical and functional outcome. The complications arised were within acceptable limits.

\section{References}

1. Colles A. On the fracture of the carpal extremity of the radius. Edin Med Surg J. 1814; 10:182.

2. Young BT, Rayan GM. Outcome following nonoperative treatment of displaced distal radius fractures in low demand patients older than 60 years. J Hand Surg [Am]. 2000; 25:19-28.

3. Fernandez DL, Jupiter JB, Newyork NY. SpringerVerlag; Fractures of the distal radius: A practical approach to management, 1996.

4. Fernandez DL. Radial osteotomy and Bowers arthroplasty for malunited fractures of the distal end of radius. J Bone Joint Surg Am. 1988; 70:1538-51.

5. Ring D, Jupiter JB. Percutaneous and limited open fixation of fractures of the distal radius. Clin Orthop. 2000; 275:105-15.

6. Cooney WP, Lindscheid R, Dobyns J. external pin fixation for unstable Colles' fracture. J Bone Joint surg [Br]. 1979; 61-B:840-5

7. Rayhack JM. The history and evolution of Percutaneous pinning of displaced distal radius fractures. Orthop Clin North Am. 1993; 24:287-300.

8. Simic PM, Weiland AJ. Fractures of the distal aspect of the radius: changes in treatment over the past two decades. J Bone Joint Surg [Am]. 2003; 85-A:552-64

9. Jupiter JB. Fractures of distal end of radius. J Bone Joint Surg Am. 1991; 73-A:461-9

10. Van Der linden W, Ericson R Colles.' fracture: how should its displacement be measured and how should it be immobilized? J Bone Joint surg Am. 1981; 63A:12858.

11. Palmer AK, Glisson RR, Werner FW. Ulnar variance determination. J Hand Surg Am. 1982; 7:376-9

12. McQueen M, Caspers J. Colles' fracture: does the anatomical result affect the final function? J Bone Joint surg [Br]. 1988; 70-B:649-51.

13. Green Dp. Pins and plaster treatment of comminuted fractures of the distal end of the radius. J Bone Joint Surg Am. 1975; 57-A:304-10.

14. Porter M, Stockley I. Fractures of the distal radius: intermediate and end results in relation to radiologic parameters. Clin Orthop. 1987; 220:241-52.

15. Azzopardi T, Ehrendorfer S, Coulton T, Abela M. A prospective randomized study of immobilization in a cast versus supplementary Percutaneous pinning. J Bone Joint Surg Br June. 2005; 87(B6):837.

16. Clancey G. Percutaneous Kirschner-wire fixation of Colles' fracture: A prospective study of thirty cases. J Bone joint Surg Am, 1984; 66-A:1008-14.

17. Rayhack JM. The history and evolution of Percutaneous pinning of displaced distal radius fractures. Orthop Clin North Am. 1993; 24:287-300.

18. Rodriguez-Merchan EC. Plaster cast versus Percutaneous pin fixation for comminuted fractures of the distal radius in patients between 46 and 65 years of age. J Orthop Trauma. 1997; 11:212-17.

19. Green DP. Pins and plaster treatment of comminuted fractures of distal end radius. J Bone Joint Surg Am. 1975; 57:304-10.

20. Abhishek K Das, Nandkumar Sundaram, Thiruvengita G Prasad. Percutaneous pinning for non-comminuted extra articular fractures of distal radius. Indian J Orthop. 2011; 45(5):422-6. 